\title{
The Role of Knowledge Sharing on Employees' Innovation Initiatives
}

\author{
Neeni Masih, Narumon Sriratanaviriyakul, Jamal El-Den ${ }^{+}$and Sami Azam \\ Charles Darwin University, Australia
}

\begin{abstract}
Knowledge sharing (KS) is one of the pillars among the factor in knowledge management. There are numerous ways in which knowledge sharing might be beneficial to organizational productivity, competitiveness and innovative initiatives. Dialogue delivery involved during knowledge sharing, often lead to generation of new ideas, which form the ground for the nurturing of new knowledge. KS helps in marketing effectiveness and enhances organizational innovativeness. The purpose of this research is to investigate the role of employees' knowledge sharing, and to what extent KS affect their innovative thinking/ initiatives. The research will first investigate the general roles knowledge management and knowledge sharing plays on organizational performance and later focus on how the sharing of personal/individual knowledge affects the employees overall critical thinking and consequently their innovation initiatives and innovation. The research will also discuss the effects on employees' KS on groups and consequently on the group's overall innovative ideas. Generally, employees resist sharing what they know as they believe they would lose competitiveness. Such thinking not only prevents the learning within the group but also affects the employees' innovation initiatives as we posit is the only way to be more creative is to be exposed to other's ideas which in most circumstances act as triggers for ideas and innovations generation. We argue that, for innovation to happen, KS is essential key factor in the process. The paper introduced a framework which demonstrates how knowledge sharing takes place in an organization by identifying the factors required for the sharing to take place. In addition, the paper argues that these factors are the drive for and trigger employees' innovation and consequently increase organizational learning.
\end{abstract}

Keywords: knowledge sharing, innovation, knowledge management

\section{Introduction}

Increased requirement for flexibility and speed in production associated with constant drop in technology prices remains critical issues compelling today's organizations to compete in fast customer satisfaction to gain market competitiveness. In order to attain a strong market position, organizations are forced to constantly strive for innovative ideas for their services and products, hence increase their employees' sharing of their knowledge as a means to ensure new idea generation. Innovation is a significant variable for all business units today, which relies mainly on efficient knowledge management and knowledge sharing amongst employees [1]. The nurture of employee's ideas through communication and exchange of expertise is a decisive factor in promoting new innovative ideas. The paper highlights on these factors and seeks to investigate the role of knowledge sharing in improving employees' innovation initiatives.

\section{Background}

Hislop [2] posited that knowledge should be regarded as a key determinant of a long term survival of today's organizations. However, the efficient management and sharing amongst employees also plays a crucial and primary role in attaining a competitive edge. Considerable studies have focused on this domain trying to identify the relationship between knowledge management and innovation. Based on previous researchers' work, the effective adoption and implementation of knowledge creation, sharing, future usage

\footnotetext{
+ Corresponding author.

E-mail address: jamal.el-den@cdu.edu.au
} 
and management is essential and crucial for efficient use of employees' know-how if organizations are to achieve competitiveness. Although most research focused on knowledge management in its entirety, less research addressed the role of employees' knowledge sharing on organizations productivity and innovativeness.

Accordingly, effective knowledge sharing has varied implications on the company' performance as it directly affects business units growth potential, motivates employees and exposes them to varied skills and information, generates new ideas, increases operational efficiency, limits skill gap and creates a sense of purpose amongst employees [3]. These aspects in turn accentuate knowledge, experiences and employees' ability, making them more capable to develop innovative business processes for better growth [4]. Current research lacks providing answers to how value creation capabilities can be increased as a result of effective knowledge sharing that remains crucial for greater innovation and this research will try to address this gap.

\section{Issues in Knowledge Sharing}

Knowledge management is a process of capturing organizational goals with the help of strategy driven motivations, as well as providing facilities of managing knowledge to workers, so that they can enhance their capability to investigate data and information through different available sources of information, experience, know-how, culture, etc [5].

There usually are insufficient HRD professionals in jobs because they outnumbered the employees, and therefore are unable to provide the best knowledge to all the employees [6]. The majority of researchers fail to understand the needs of the employees and they cannot provide effective and efficient methods of preaching knowledge to their employees. Communication gap is another major aspect that often leads to ineffective knowledge sharing among the employees. Due to the extreme competition, employees tend not to share the knowledge with other employees and this leads decrease in organizational innovation initiatives [7]. Most organizations have vertical hierarchy, which creates a barrier in communication between employees and higher management. Fear among the employees is mainly due to inferiority complex and employees are not willing to share knowledge with their superiors [8]. Moreover, body language is another reason for communication gap among the employees and this ultimately leads to mistrust among the employees. The employees with higher knowledge often do not share with other employees and this leads to knowledge gap. Consequently, sharing is not a by-product within organizations and it advocates for a cultural change in the organization as well as closing the gap between employees and higher management. Employees must be encouraged to share, and this can only be done if the employees feel "safe" to do so.

\subsection{Critical Analysis of the Importance of Knowledge Management and Its Impact on Organizational Performance}

Most organizations are knowledge-based, where, the information and knowledge available to organizations are regarded as essential and critical resources [9]. Knowledge is also considered to be a core competence and a major performance driver for most organizations. Thus, a significant key for value creation within the business comes from placing considerable emphasis on generating and managing knowledge. Knowledge management is the integrated process of knowledge creation, transfer, storage and management [10]. This multidisciplinary approach is regarded as the most important aspect for business, which caters to fulfill major organizational objectives through continuous improvement and innovation. Thus, knowledge management mainly focuses on efforts towards improved performance, sharing of experiences and learned lessons and competitive advantage, which often overlap with organizational learning. Effective knowledge management affects and facilitates decision making capabilities, stimulates innovation and cultural change and builds a learning culture within organization [11]. All three-core advantages directly impact upon organizational performance and productivity. Valid and critical knowledge is essential because the knowledge received by the employee would be applied by the employees in the field of work [4]. Ineffective and vague knowledge would hamper the employee's performance thereby reducing the efficiency of the company's performance. Hence, proper identification of valid knowledge is crucial before the employees are trained with it. Employees, if properly trained with the knowledge of work, will effectively improve the performance of the employee in a better way [3]. Hence, there is a direct link between the 
knowledge gain and employee performance as sharing of knowledge from one employee to another improves the overall performance of an organization [12]. Proper knowledge improves the innovative ideas of the employees and helps the employees to create new ideas for the betterment of the job.

\subsection{Knowledge Management, Innovation and Cultural Change}

Efficient knowledge management and knowledge sharing generates and encourages free flow of ideas. It actively manages data and information available to all employees and increases their capability to use induced knowledge to create more efficient business plans. Teams benefits from knowledge of other employees and individual skills, which increases expertise and power of overall workforce [13]. Varying backgrounds and cultural differences between employees also accentuates this trend leading to a more desirable stimulus for growth. Effective knowledge management with the help of systematic and collective processes also decrease tendency of employees to repeat and commit same mistakes. This dramatically increases and improves quality of services and products. Better knowledge regarding customer needs, stakeholder needs, industry needs and employee needs also increases capability of workers to strategically develop efficient and suitable policies and strike a balance between interests of all stakeholders to attain greater business results [14]. Thus, this culture for change facilitates innovation and allows employees to respond faster, thus providing organizations a competitive advantage over others. Ecological knowledge management theory gains attention here. It stresses on relationships, people and various learning communities in relation to knowledge management. It also emphasizes on multiple interactions between and amongst employees and companies and critical external and internal factors influencing and drawing people closer to engage in effective knowledge sharing. However, Obeidat et al. [15] argued that knowledge management systems are mainly complex and costly. Hence, many small business units are unable to implement such strategies for business gains. Scholars also stressed on the fact that sufficient skill and knowledge is required to handle and use knowledge management systems. Thus, for collecting and recording right data suitably, employees must first be trained.

\subsection{The Effects of Knowledge Sharing on Organizational Learning Culture}

A proper knowledge management system helps in generating a learning culture as it creates an environment where all workers continuously engage in self-assessment and seeks to find effective ways for improvement [10]. This strategy and culture helps employees to better identify their loopholes, disadvantages and advantages, which lays down specific paths for better performance in the future. Even though most scholars agreed with this claim, many also identified possible disadvantages and negative aspects of knowledge management. Many organizations tend to create a repository of information that mainly remains disregarded and useless [11]. Absence of stimulus for an appropriate knowledge base and absence of practical benefit develops a vicious circle within knowledge management processes that in turn tends to harm organizational effectiveness. It is essential for an organization to constantly upgrade products and services in order to spread the company worldwide and create innovations [7]. Therefore, it is essential to properly train the employees with adequate knowledge and also update the employees with new technologies and services so that the organization can constantly upgrade [6]. Organizational learning culture constantly encourages new technologies and systems and affects the knowledge sharing. New use of techniques requires proper education and knowledge and will effectively improve the overall performance of the organization. Organizational learning culture enables the employees to understand the disadvantages and inefficiencies of the employees and will eventually help the employees to improve the performance [8].

\section{Factors Affecting Knowledge Management}

Innovation remains the greatest payoff of a suitable knowledge management strategy [1]. However, various factors influence the success of knowledge management initiatives. These factors include culture, technology, organizational adjustment, leadership, knowledge resources, employee motivation and willingness to share, knowledge activities and various other external factors. All such factors can be broadly classified as managerial influences, environmental influences and resource influences. 
Table 1: Summary of current literary factors considered vital for organizational knowledge sharing and innovation

\begin{tabular}{|c|c|}
\hline Literature & Factors considered \\
\hline $\begin{array}{l}\text { Knowledge } \\
\text { management } \\
\text { practices \& } \\
\text { innovation } \\
\text { performance: a } \\
\text { literature } \\
\text { review [16] }\end{array}$ & $\begin{array}{l}\text { - Knowledge management plays an important role in creative thinking. } \\
\text { - Leadership, policies and strategies lead to increase or decrease the innovation. } \\
\text { - } \text { Centralized leadership is direct way of innovation. } \\
\text { - } \text { innovation. } \\
\text { To employees being regularly innovative, organizations should be always supportive } \\
\text { - } \quad \text { Rewards their efforts of learning and gaining new knowledge. } \\
\text { - Innovation is increased by communication, and through exchanging of ideas and } \\
\text { information, therefore quick feedback and trust can help in improving it. }\end{array}$ \\
\hline $\begin{array}{l}\text { Intellectual } \\
\text { Stimulation } \\
\text { Effects on } \\
\text { Knowledge } \\
\text { Sharing, } \\
\text { Innovation and } \\
\text { Firm } \\
\text { Performance } \\
{[17]}\end{array}$ & $\begin{array}{l}\text { - Top management support leads to knowledge sharing in an organization } \\
\text { - Intellectual stimulation as one dimension of transformational leadership has dedicated and } \\
\text { concise impact on experiential sharing and explicit knowledge sharing. } \\
\text { - Explicit knowledge conducted by employees results in innovation in organizations } \\
\text { - Creativity can be increase by sharing of reports hence increases creating new products. } \\
\text { - Sharing of past experience among employees has no effect on product innovation. } \\
\text { - Psychological barriers that restricted to share knowledge can be improved by intellectual } \\
\text { stimulation of transformational leaders for managerial implication } \\
\text { - Intellectual stimulation can be increased in an organization by focus group discussions } \\
\text { within organization regularly. }\end{array}$ \\
\hline $\begin{array}{l}\text { Knowledge } \\
\text { Management } \\
\text { and the } \\
\text { Effectiveness of } \\
\text { Innovation } \\
\text { Outcomes: The } \\
\text { Role of Cultural } \\
\text { Barriers [18] }\end{array}$ & $\begin{array}{l}\text { - Knowledge management strategies (explicit-tacit oriented and external-internal oriented) } \\
\text { improves the knowledge base. } \\
\text { - Innovation-knowledge Link can be improved through cultural barrier. } \\
\text { - Innovation can be distracted in organization through cultural aspects like conflict among } \\
\text { employees, decrement of motivation and resistance to change. } \\
\text { - As per many researches, cultural barriers are in charge of advancement of learning } \\
\text { through exploitation, towards the accomplishment of the particular organizational } \\
\text { objective. Therefore, they increase compliance than innovation. } \\
\text { - Inability of organizational to remove cultural barriers, make the organizations unable to } \\
\text { invent, explain and explore new knowledge and hence upcoming opportunities. There } \\
\text { should be effective organizational environment for employees to stand against the cultural } \\
\text { barriers. }\end{array}$ \\
\hline $\begin{array}{l}\text { Mediating Role } \\
\text { Of Knowledge } \\
\text { Sharing On } \\
\text { Information } \\
\text { Technology } \\
\text { And Innovation } \\
\text { [19] }\end{array}$ & $\begin{array}{l}\text { - Information technology has effective result on knowledge sharing. } \\
\text { - Knowledge sharing leads to organization innovation } \\
\text { - Innovativeness is the root to success in the ongoing business and competitiveness. } \\
\text { - Tr boost innovation in organization, both tacit and explicit knowledge are needed. } \\
\text { - Information technology can be considered as organizational factor to increase knowledge } \\
\text { - IT infring and innovation. } \\
\text { - knowledge sharing of employees and thus increase the product and process innovation. } \\
\text { Investment in R\&D of the organization }\end{array}$ \\
\hline $\begin{array}{l}\text { Knowledge } \\
\text { sharing and } \\
\text { firm innovation } \\
\text { capability: an } \\
\text { empirical study } \\
\text { [20] }\end{array}$ & $\begin{array}{l}\text { - Individual factors are directly related with knowledge sharing process. } \\
\text { - The increment of level of the enjoyment by the management leads to a better knowledge } \\
\text { sharing since employees can happily help each other and knowledge sharing occurs } \\
\text { - Managers should encourage social exchange which would help towards developing and } \\
\text { sustaining new knowledge. } \\
\text { - Managers should give feedback in order to improve knowledge-self efficacy of } \\
\text { employees. } \\
\text { - Facility of knowledge sharing by top management is necessary. } \\
\text { - Reward system like incentives, bonus does not lead to more knowledge sharing. }\end{array}$ \\
\hline
\end{tabular}

Based on the discussions of the factors in Table 1, we developed a framework (Table 2) taking into account the above identified factors based on employees' intentions/ willingness to share, medium of knowledge sharing and form of innovation. 
Table 2: Factors based on intention/willingness to share, knowledge sharing and form of innovation

\begin{tabular}{|c|c|c|}
\hline Intention/willingness to share & Medium of sharing & Form of innovation \\
\hline $\begin{array}{ll}\text { - } & \text { Support from management } \\
\text { - } & \text { Intellectual stimulation } \\
\text { - } & \text { Explicit knowledge } \\
\text { - } & \text { Transformation leaders }\end{array}$ & $\begin{array}{ll}- & \text { Reports and documents } \\
\text { - } & \text { Dialogue delivery of experience } \\
\text { - } & \text { Group discussion }\end{array}$ & - $\quad$ Product innovation \\
\hline $\begin{array}{ll}\text { - } & \text { Leadership and policies and } \\
\text { - } & \text { strategies } \\
\text { - } & \text { Decremovative culture and room } \\
& \text { mentoring } \\
\text { - } & \text { Supporting organizational system } \\
\text { - } & \text { and structures } \\
\text { - } & \text { Coward System } \\
\text { - } & \text { Feedback and trust }\end{array}$ & - $\quad$ Information and Ideas & $\begin{array}{ll}- & \text { Product innovation } \\
- & \text { Process innovation }\end{array}$ \\
\hline $\begin{array}{ll}- & \text { Information Technology } \\
\text { - } & \text { High cost in R\&D investment } \\
\text { - } & \text { Training programs in IT } \\
\text { - } & \text { Information Technology } \\
& \text { Infrastructure }\end{array}$ & $\begin{array}{ll}\text { - } & \text { Transforming Tacit knowledge to } \\
\text { - } & \text { LAplicit knowledge } \\
\text { - } & \text { Intranet } \\
\text { - } & \text { Video conferencing System } \\
\text { - } & \text { Social Network } \\
\end{array}$ & $\begin{array}{ll}- & \text { Product innovation } \\
- & \text { Process Innovation }\end{array}$ \\
\hline $\begin{array}{ll}\text { - } & \text { Cultural barriers } \\
\text { - } & \text { Existence of conflict among } \\
\text { individual } \\
\text { - } & \text { Lack of motivation } \\
\text { - } & \text { Resistance to change } \\
\end{array}$ & $\begin{array}{ll}\text { Removal of cultural barrier } \\
\text { (knowledge sharing atmosphere) }\end{array}$ & $\begin{array}{l}\text { - } \quad \text { Sharing of information and } \\
\text { ideas and experience }\end{array}$ \\
\hline 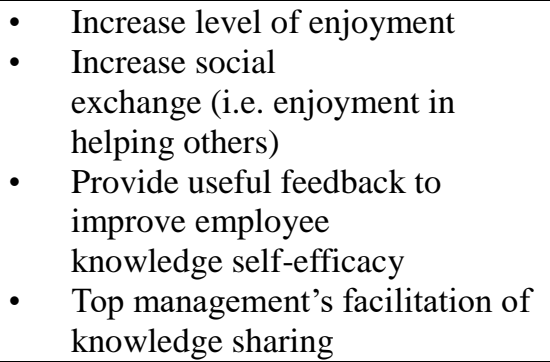 & $\begin{array}{l}\text { Helping others (dialogue } \\
\text { delivery) }\end{array}$ & $\begin{array}{ll}\text { - } & \text { Product innovation } \\
\text { - } & \text { Process innovation } \\
\text { - } & \text { Technological innovation }\end{array}$ \\
\hline
\end{tabular}

Table 3 identifies common and uncommon factors in respect to intention or willingness to share knowledge and Table 4 depicts common and uncommon factors in respect to medium/platform to share

Table 3: Common and uncommon factors in respect to intention/willingness to share knowledge

\begin{tabular}{|c|c|}
\hline Common factors & Uncommon factors \\
\hline $\begin{array}{ll}\text { - } & \text { Top management support } \\
\text { - } & \text { Reward system } \\
\text { - } & \text { Feedback to employees or motivation } \\
\text { - } & \text { Leadership }\end{array}$ & $\begin{array}{ll}\text { - } & \text { Enjoyment satisfaction (happiness/enjoyment) } \\
\text { - } & \text { Cultural barriers } \\
\text { - } & \text { Informatict among individuals } \\
\text { - } & \text { High investment in R\&D investment } \\
\text { - } & \text { Decrement of training and mentoring }\end{array}$ \\
\hline
\end{tabular}

Table 4: Common and uncommon factors in respect to medium/platform to share

\begin{tabular}{|c|c|}
\hline Common factors & Uncommon factors \\
\hline $\begin{array}{ll}\text { - } & \text { Dialogue delivery } \\
\text { - } & \text { Reports and documents } \\
\text { - } & \text { Sharing experience }\end{array}$ & $\begin{array}{ll}\text { - } & \text { Intranet } \\
\text { - } & \text { Videoconferencing system } \\
\text { - } & \text { Social network } \\
\text { Removal of cultural barriers }\end{array}$ \\
\hline
\end{tabular}

\section{Proposed Research Framework}

The research's framework is drawn from a comparative analysis of current literature where prominent authors have identified factors, some are used often (common) and some are not (uncommon), which affect employees' innovation as well as their innovation initiatives as a result of increasing their incentives and willingness to share and consequently their knowledge sharing. The framework highlights these factors and 
identifies those factors that are common among most of the researchers as well as those that are not common and which are uniquely addressed in this paper. The framework was developed based on these factors and shows how they affect the employees' intentions as well as their willingness to share. The framework also added the media/platform for the sharing and how combined with the factors would affect the employees' intentions to share as currently the "media", which ever it is, plays an integral role in the employees communication, knowledge transfer, knowledge sharing and consequently has a vital role on increasing the employees' willingness to share what they know.

The framework illustrates literary factors which are frequently used by researchers (common factors) to promote employees intention/willingness and highlights which are not frequently used (uncommon factors) which also have effects on the employees' intention/willingness to share along with media/ platform of sharing. In addition, we introduced new types such as, intranet and social networking which had not been addressed previously. We posit that including media/ platform as factors which promote intention/ willingness to share is integral for better investigation of the employees' willingness to share and to innovate. Other factors that can be directly responsible for boosting up the innovation capabilities of employees and let the innovation happen in organization can be employee's incentives to innovate. It has been investigated on basis of existing finding that incentives could anything accept the money itself, that could be promotions, tours etc. The reason behind eliminating the money for incentives is that after a period of time employees' expectations regarding additional rewards grew as well, which ultimately results in unsatisfied employees and zero outcomes for organization.

The framework shows the effects and relationships of the identified common/uncommon factors and the medium/platform, on employees' innovation and knowledge sharing in organizations (Figure 1).

Hypothesis 1: Common factors increase the employee's intention/ willingness to share.

Hypothesis 2: Uncommon factors increase the employee's intention/ willingness to share.

Hypothesis 3: Common factors positively affect Media/platform adoption for Knowledge Sharing

Hypothesis 4: Uncommon factors positively affect Media/platform adoption for KS

Hypothesis 5: The adoption of Media/Platform positively increases the employees' knowledge sharing intention and/or willingness

Hypothesis 6: The employees' intention/willingness to share what they know increases the knowledge sharing

Hypothesis 7: The adoption of Media/Platform for knowledge sharing among employees positively affects their overall knowledge sharing

Hypothesis 8a: The existence of incentive for sharing increases the sharing among employees

Hypothesis 8b: the existence of incentives to share increases employees' innovation capabilities

Hypothesis 9: knowledge sharing promotes employees' innovation capabilities

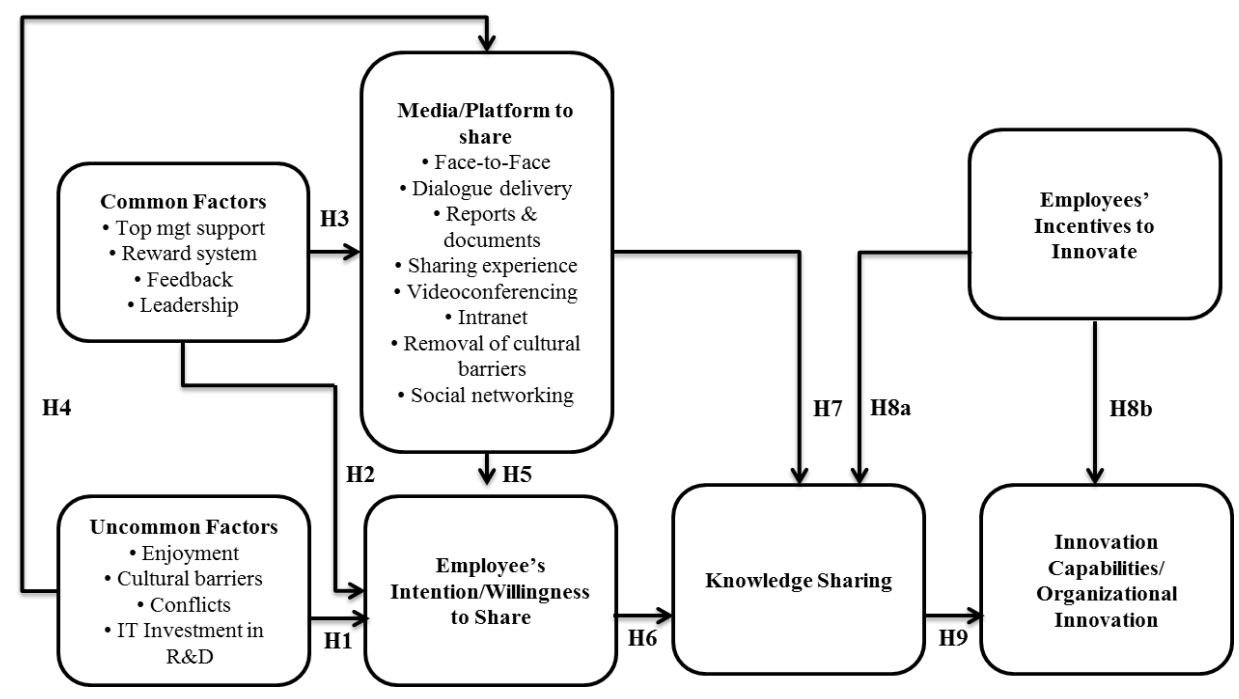

Fig. 1: Proposed research framework. 


\section{Conclusion}

The paper investigated the role of knowledge sharing in promoting organizational innovativeness. It provided a summary the factors which prominent authors have identified which, in their opinion, affect the innovation initiatives and innovation in general in organizations. The paper also introduced some uncommon factors which are either poorly addressed or never addressed in the literature which also have effects on employees' innovative initiatives. Based on these factors, the paper introduced a framework which shows the relationship between these factors, their link to employees' knowledge sharing incentives and willingness as well as on their overall knowledge sharing. The paper posits that employees should be given incentives by the management in order to increase both their knowledge sharing and innovative capabilities. The paper also posits that there are factors which are integral in increasing employees' intentions and willingness to share and introduced these factors. In addition, the paper stressed that the choice of medium of knowledge sharing and a supportive platform will also reflects positively on the employees' innovation.

\section{References}

[1] Fischer, M.M. and J. Fröhlich, Knowledge, complexity and innovation systems. 2013: Springer Science \& Business Media.

[2] Hislop, D., Knowledge management in organizations: A critical introduction. 2013: Oxford University Press.

[3] Alegre, J., K. Sengupta, and R. Lapiedra, Knowledge management and innovation performance in a high-tech SMEs industry. International Small Business Journal, 2013. 31(4): p. 454-470.

[4] Noruzy, A., et al., Relations between transformational leadership, organizational learning, knowledge management, organizational innovation, and organizational performance: an empirical investigation of manufacturing firms. The International Journal of Advanced Manufacturing Technology, 2013. 64(5-8): p. 10731085.

[5] Sriratanaviriyakul, N. and J. El-Den, A Conceptual Model for Knowledge Sharing Among Small Groups Using Discussion Cases. International Journal of Computing Academic Research (IJCAR), 2016. 5(4): p. 177-186.

[6] Bammer, G., A. Michaux, and A. Sanson, Bridging the'Know-Do'Gap: Knowledge brokering to improve child wellbeing. 2013: ANU Press.

[7] Fukuda-Parr, S. and C. Lopes, Capacity for development: new solutions to old problems. 2013: Routledge.

[8] Epstein, M.J. and A.R. Buhovac, Making sustainability work: Best practices in managing and measuring corporate social, environmental, and economic impacts. 2014: Berrett-Koehler Publishers.

[9] Urbancova, H., Competitive advantage achievement through innovation and knowledge. Journal of Competitiveness, 2013. 5(1).

[10] Garriga, H., G. Von Krogh, and S. Spaeth, How constraints and knowledge impact open innovation. Strategic Management Journal, 2013. 34(9): p. 1134-1144.

[11] Donate, M.J. and J.D.S. de Pablo, The role of knowledge-oriented leadership in knowledge management practices and innovation. Journal of Business Research, 2015. 68(2): p. 360-370.

[12] Becerra-Fernandez, I. and R. Sabherwal, Knowledge management: Systems and processes. 2014: Routledge.

[13] Lai, Y.-L., et al., The effects of industry cluster knowledge management on innovation performance. Journal of Business Research, 2014. 67(5): p. 734-739.

[14] Meihami, B. and H. Meihami, Knowledge Management a way to gain a competitive advantage in firms (evidence of manufacturing companies). International letters of social and humanistic sciences, 2014. 3: p. 80-91.

[15] Obeidat, B.Y., et al., The impact of knowledge management on innovation: An empirical study on Jordanian consultancy firms. Management Research Review, 2016. 39(10): p. 1214-1238.

[16] Githii, S., Knowledge management practices and innovation performance: a literature review. Journal of Business and Management (IOSR-JBM), 2014. 16(2): p. 89-94.

[17] Utami, M.M., How intellectual stimulation effects knowledge sharing, innovation and firm performance. International Journal of Social Science and Humanity, 2013. 3(4): p. 420. 
[18] Leal-Rodríguez, A., et al., Knowledge Management and the Effectiveness of Innovation Outcomes: The Role of Cultural Barriers. The Electronic Journal of Knowledge Management, 2013. 11(1): p. 62-71.

[19] Kaewchur, O., P. Anussornnitisarn, and Z. Pastuszak, The mediating role of knowledge sharing on information technology and innovation. International Journal of Management, Knowledge and Learning, 2013. 2(2): p. 227242.

[20] Lin, H.-F., Knowledge sharing and firm innovation capability: an empirical study. International Journal of manpower, 2007. 28(3/4): p. 315-332. 